\title{
Protein phosphorylation in plant immunity: insights into the regulation of pattern recognition receptor-mediated signaling
}

\author{
Chang-Jin Park, Daniel F. Caddell and Pamela C. Ronald*
}

Department of Plant Pathology and the Genome Center, University of California at Davis, Davis, CA, USA

Edited by:

Vardis Ntoukakis, University of

Warwick, UK

\section{Reviewed by:}

Christof Rampitsch, Agriculture and

Agri-Food Canada, Canada

Sixue Chen, University of Florida, USA

\section{${ }^{*}$ Correspondence:}

Pamela C. Ronald, Department of Plant Pathology and the Genome Center, University of California at Davis, One Shields Avenue,

Davis, CA 95616, USA.

e-mail: pcronald@ucdavis.edu

\begin{abstract}
Plants are continuously challenged by pathogens including viruses, bacteria, and fungi. The plant immune system recognizes invading pathogens and responds by activating an immune response. These responses occur rapidly and often involve post-translational modifications (PTMs) within the proteome. Protein phosphorylation is a common and intensively studied form of these PTMs and regulates many plant processes including plant growth, development, and immunity. Most well-characterized pattern recognition receptors (PRRs), including Xanthomonas resistance 21, flagellin sensitive 2, and elongation factor-Tu receptor, possess intrinsic protein kinase activity and regulate downstream signaling through phosphorylation events. Here, we focus on the phosphorylation events of plant PRRs that play important roles in the immune response. We also discuss the role of phosphorylation in regulating mitogen-associated protein kinase cascades and transcription factors in plant immune signaling.
\end{abstract}

Keywords: EFR, FLS2, pattern recognition receptor, plant immunity, post-translational modifications, protein phosphorylation, XA21

\section{INTRODUCTION}

Proteins can undergo various post-translational modifications (PTMs) that affect their conformation, activity, stability, and localization. These PTMs, which are often reversible, are highly specific regulators of many cellular processes (Jensen, 2004). Currently, more than 300 types of PTMs have been described including ubiquitination, sumoylation, sulfation, glycosylation, and phosphorylation (Stulemeijer and Joosten, 2008; Ghelis, 2011). Phosphorylation is one of the most predominant PTMs and onethird of all eukaryotic proteins are thought to be phosphorylated (Olsen et al., 2006). Protein phosphorylation in eukaryotes predominantly occurs on serine (Ser) and threonine (Thr) residues, whereas phosphorylation on tyrosine (Tyr) residues is much less abundant (de la Fuente van Bentem and Hirt, 2009). Based on a recent large-scale phosphorylation study, the relative abundances of pSer, pThr, and pTyr were estimated to be 82.7, 13.1, and 4.2\% in Arabidopsis and 84.8, 12.3, and 2.9\% in rice (Sugiyama et al., 2008; Nakagami et al., 2010). Phosphorylation occurring on unusual residues such as histidine, lysine, and arginine (Besant and Attwood, 2005; Ciesla et al., 2011) will not be reviewed, because their involvement in plant immunity has not yet been elucidated.

A large body of evidence demonstrates that phosphorylation is essential for immune responses in animals and plants. For example, in animals, nearly 7,000 phosphorylation sites on more than 1,800 phosphoproteins were identified in response to lipopolysaccharide activation (Weintz et al., 2010). In Arabidopsis, more than 1,170 phosphopeptides from 472 phosphoproteins were identified after treatments with flg22 or xylanase, both of which elicit immune responses in Arabidopsis cell cultures (Benschop et al.,
2007). These results indicate that many proteins are differentially phosphorylated and that the phosphorylation events are essential to both animal and plant immune responses. In this review, we focus primarily on phosphorylation events mediated by plant pattern recognition receptors (PRRs) that play important roles in the immune response.

\section{PATTERN RECOGNITION RECEPTORS IN RICE AND ARABIDOPSIS}

Plant innate immunity is controlled by a set of defined receptors referred to as PRRs. A more detailed description of PRRs can be found in recent reviews (Ronald and Beutler, 2010; Schwessinger and Ronald, 2012). In general, recognition of conserved microbial signatures (also called pathogen-associated molecular patterns, PAMP) by PRRs triggers mitogen-associated protein kinase (MAPK) activation, production of reactive oxygen species (ROS), $\mathrm{Ca}^{2+}$ burst, transcriptional reprogramming, hormone biosynthesis, and deposition of callose in the cell wall (Nurnberger et al., 2004; Ronald and Beutler, 2010; Segonzac and Zipfel, 2011).

The rice PRR, Xanthomonas resistance 21 (XA21), recognizes a conserved sulfated peptide called $\mathrm{AxY}^{\mathrm{S}} 22$, derived from the Xanthomonas oryzae pv. oryzae (Xoo) protein Ax21 (activator of XA21-mediated immunity; Lee et al., 2009). In Arabidopsis, two additional plant PRRs have been well-characterized. These are flagellin sensitive 2 (FLS2) and elongation factor (EF)-Tu receptor (EFR), which recognize the flg22 peptide from flagellated bacteria and the EF-Tu-derived peptide elf18, respectively (Gomez-Gomez and Boller, 2000; Zipfel et al., 2006). These PRRs consist of an extracellular leucine-rich repeat (LRR) domain, a transmembrane (TM) domain, a juxtamembrane 
(JM) domain, and an intracellular non-arginine-aspartate (nonRD) kinase domain (Figure 1; Dardick and Ronald, 2006; Schwessinger and Ronald, 2012).

Non-RD kinases typically carry a cysteine $(C)$, or glycine $(G)$ before the conserved catalytic aspartate (D) residue. All plant receptor kinases (RKs) characterized to date that carry the non-RD kinase motif are involved in recognition of conserved microbial signatures (Schwessinger and Ronald, 2012). In contrast, the larger group of $\mathrm{RD}$ kinases have an arginine (R) immediately preceding the conserved catalytic aspartate (D). RD kinases are known to perform more diverse functions and are often associated with developmental processes. RD kinases also work in partnership with non-RD kinases to transduce immune responses. In Arabidopsis, brassinosteroid insensitive 1 (BRI1)-associated kinase 1 (BAK1), an RD kinase, was initially identified as a positive regulator of brassinosteroid responses. BAK1 forms an in vivo ligand-dependent complex with the BRI1 receptor (Li et al., 2002; Nam and Li, 2002). Further research revealed that BAK1 is also involved in PRR-mediated signaling, physically interacting with the non-RD kinases FLS2 and EFR (Chinchilla et al., 2007, 2009; Schwessinger et al., 2011). BAK1 null mutants are compromised in their responsiveness to several other conserved microbial signatures including HrpZ (hypersensitive response and pathogenicity Z), lipopolysaccharides, and peptidoglycans (Heese et al., 2007; Shan et al., 2008). The rice ortholog of BAK1, XA21-associated kinase 1 (XAK1), is required for XA21-mediated immunity (Chen et al., unpublished). These results demonstrate that PRRs utilize coregulatory receptors carrying RD kinases as signaling partners to transduce the immune response.

\section{PHOSPHORYLATIONS OF PATTERN RECOGNITION RECEPTORS}

In accordance with an essential role of phosphorylation in immune signaling, phosphorylation of FLS2 is the first step in the FLS2mediated intracellular signaling events (Boller and Felix, 2009). De novo phosphorylation of a FLS2/BAK1 complex is clearly detectable in cells $15 \mathrm{~s}$ after the addition of flg22 using in vivo labeling with short pulses of $\left[{ }^{33} \mathrm{P}\right]$ orthophosphate (Schulze et al., 2010). Treatment with protein kinase inhibitors is able to block a broad spectrum of early defense responses (Lecourieux et al., 2002; Navazio et al., 2002; Kadota et al., 2004).

In animals, signal transduction is often regulated by phosphorylation of residues in the JM domain of RKs (Aifa et al., 2006; Thiel and Carpenter, 2007). It is now becoming clear that plant PRRs, at least XA21 and FLS2, are also phosphorylated on residues in their JM domains (Figure 1; Table 1). Targeted mutagenesis of the XA21 JM domain indicated that amino acids Ser ${ }^{686}$, Thr $^{688}$, and Ser $^{689}$ are autophosphorylated and required to maintain XA21 protein stability (Xu et al., 2006). Transgenic rice carrying XA21 mutants with alanine replacement of these three sites display partially compromised resistance compared to wildtype XA21 plants (Xu et al., 2006). Thr $^{705}$ in the XA21 JM domain is also an important phosphorylation site and also affects the autophosphorylation activity of XA21 (Chen et al., 2010b). The XA21 mutant derivatives, XA2 $1^{\mathrm{T} 705 \mathrm{~A}}$ and $\mathrm{XA} 21^{\mathrm{T} 705 \mathrm{E}}$, are both unable to transduce the XA21-mediated immune response. The importance of the JM domain in XA21-mediated immunity was also demonstrated through isolation of XA21-binding proteins (XBs). For example, the protein phosphatase 2C XB15

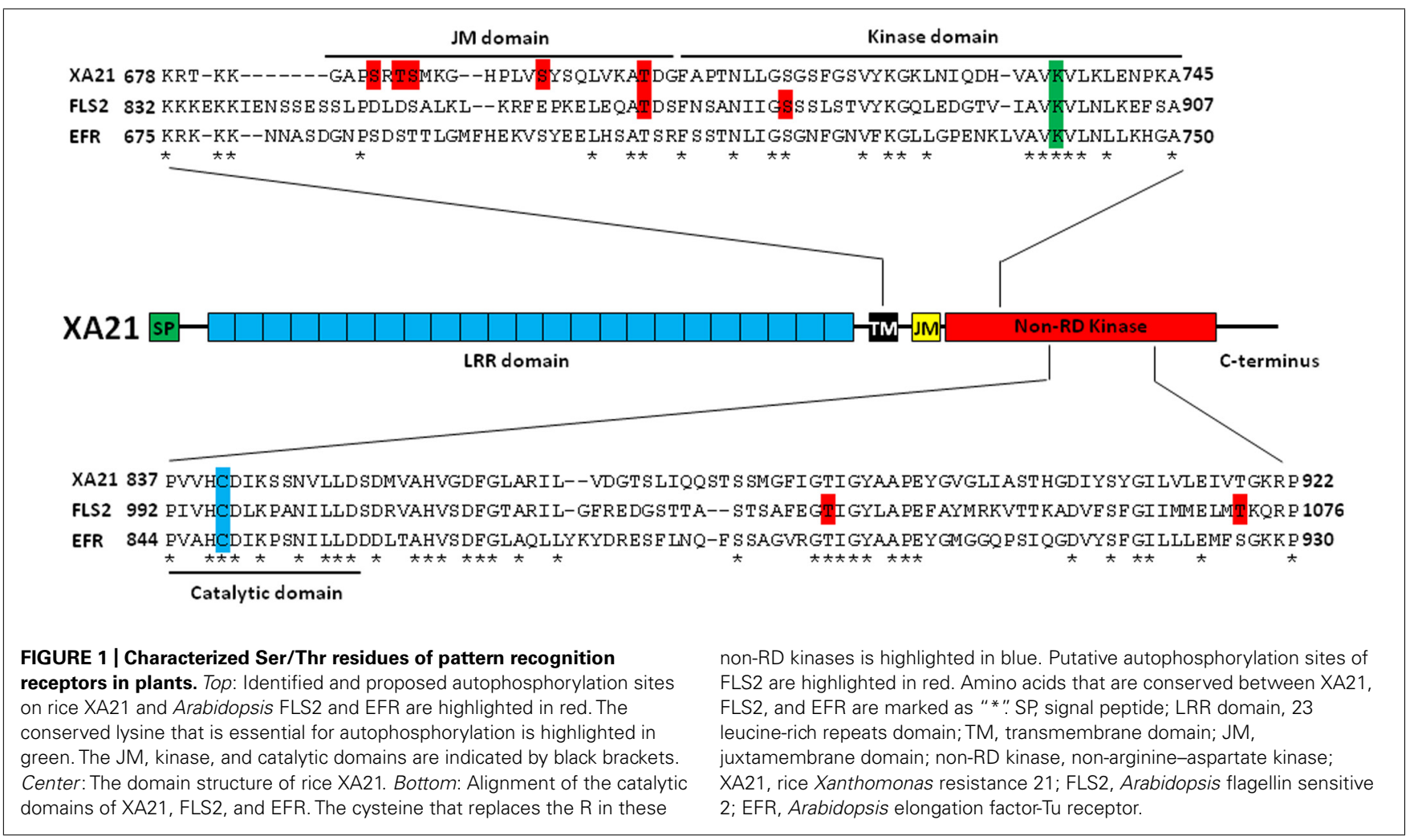


Table 1 | Summary of rice and Arabidopsis PRRs.

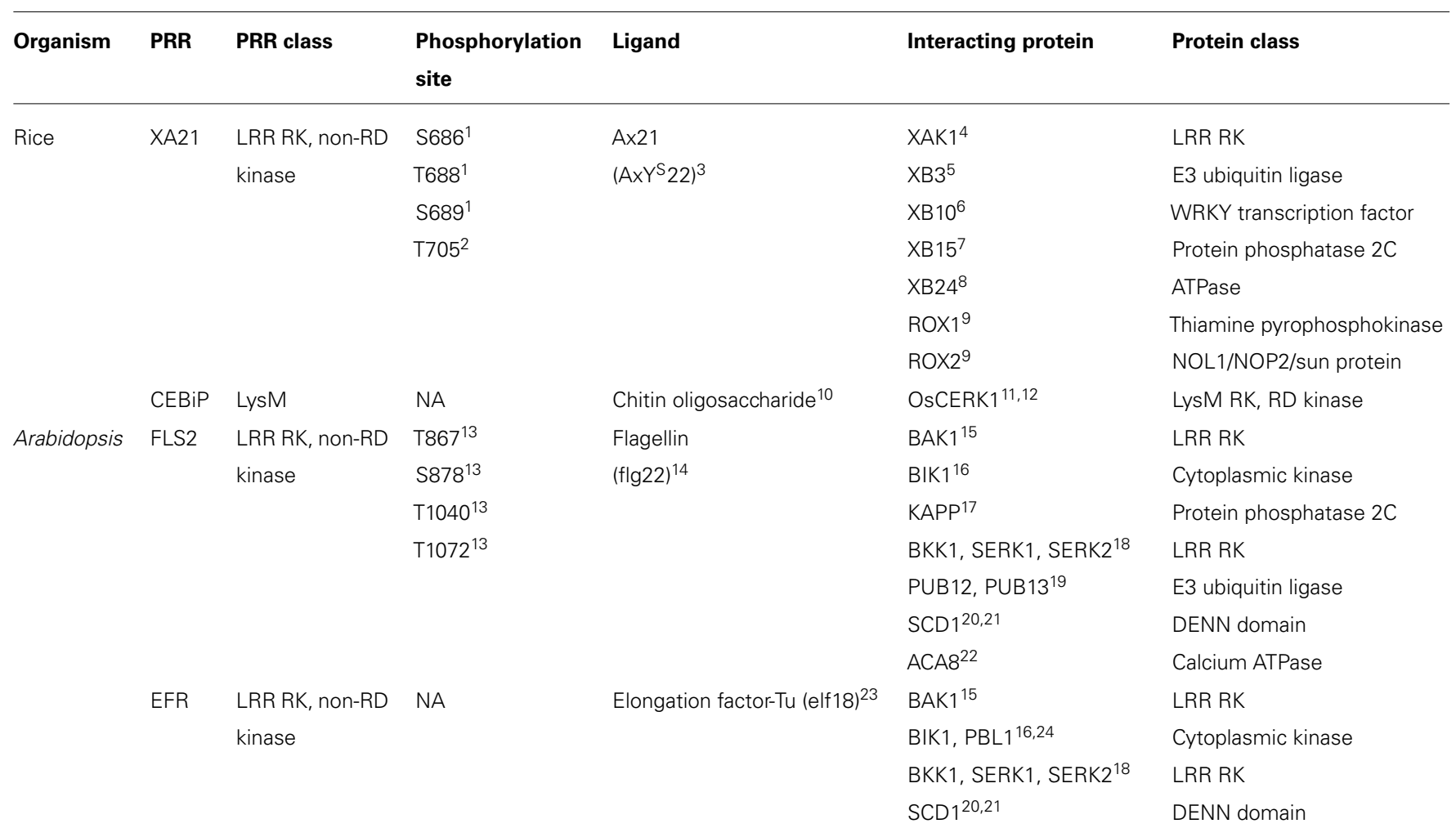

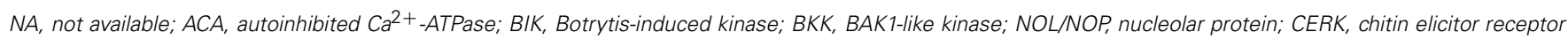

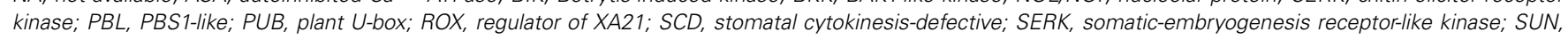
Sad1-UNC-84 homology.

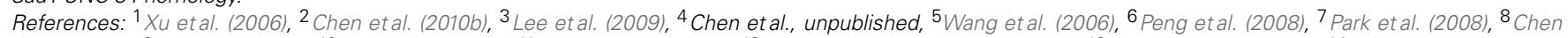

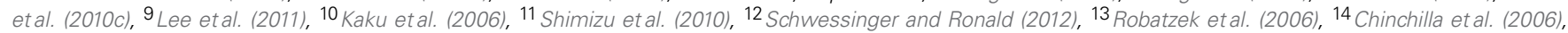

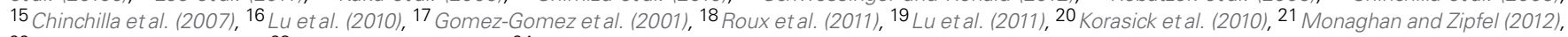
22 Frei Dit Frey etal. (2012), 23 Zipfel etal. (2006), and ${ }^{24}$ Zhang etal. (2010).

no longer interacts with XA2 $1^{\mathrm{S} 697 \mathrm{~A}}$, indicating that Ser697 in the JM domain is critical for interaction with XB15 (Park et al., 2008). Autophosphorylated XA21 is dephosphorylated by XB15 in vitro, suggesting that the function of $\mathrm{XB} 15$ is to attenuate the XA21-mediated innate immune response. The ATPase XB24 also associates with the XA21 JM domain and uses ATP to promote phosphorylation of certain Ser/Thr sites on XA21, keeping the XA21 protein in an inactive state. Upon recognition of sulfated Ax21, the XA21 kinase disassociates from XB24 and is activated, triggering downstream defense responses (Chen et al., 2010c; Figure 2).

In Arabidopsis, the FLS2 JM residue Thr ${ }^{867}$ appears to be analogous to $\mathrm{Thr}^{705}$ in XA21 (Figure 1; Table 1; Chen et al., 2010b) and is also essential for the function of FLS2 (Robatzek et al., 2006). FLS2 ${ }^{\mathrm{T} 867 \mathrm{~V}}$ inhibits FLS2 internalization and response to flg22, indicating that both processes are intimately connected (Robatzek et al., 2006). Although the FLS2 ${ }^{\mathrm{T} 867 \mathrm{~V}}$ mutation had no effect on flg22-binding, FLS2 ${ }^{\text {T867V }}$ mutant lines were insensitive to flg22 and displayed an enhanced disease susceptibility phenotype when challenged with pathogenic Pseudomonas syringae. Microscopic analysis of transgenic plants expressing FLS2 ${ }^{\mathrm{T} 867 \mathrm{~V}}$-GFP showed normal cell membrane localization of the mutant FLS2 protein.
However, FLS2 ${ }^{\mathrm{T} 867 \mathrm{~V}}$ endocytosis is strongly reduced after flg22 treatment, suggesting that phosphorylation of FLS2 ${ }^{\mathrm{T} 867}$ plays an important role in endocytosis. Further study is needed to determine if Thr ${ }^{867}$ of FLS2 is essential for FLS2 autophosphorylation in Arabidopsis and if $\mathrm{Thr}^{705}$ of XA21 is critical for XA21 endocytosis in rice.

Four FLS2 amino acids were shown to be critical to FLS2 function using site-directed mutagenesis. Seedling growth of Arabidopsis transgenic lines expressing FLS2 ${ }^{\mathrm{T} 867 \mathrm{~V}}$, FLS2 ${ }^{\mathrm{T} 1040 \mathrm{~A}}$, FLS2 ${ }^{\mathrm{S} 878 \mathrm{~A}}$, and FLS2 ${ }^{\mathrm{T} 1072 \mathrm{~A}}$ were inhibited by flg22 treatment. Three of these mutations (FLS2 ${ }^{\mathrm{T} 867 \mathrm{~V}}, \mathrm{FLS} 2^{\mathrm{T} 1040 \mathrm{~A}}$, and FLS2 ${ }^{\mathrm{T} 1072 \mathrm{~A}}$ ) also abolished flg22-induced generation of ROS (Robatzek et al., 2006). It is not known if these sites are phosphorylated or if they are required for kinase activity.

In all protein kinases, it is well known that a conserved lysine residue is responsible for a phosphotransfer reaction (Carrera et al., 1993). The importance of this lysine for kinase function has been demonstrated for plant PRRs. For example, the Lys ${ }^{736}$ residue inside the XA21 kinase domain is essential for XA21 autophosphorylation (Liu et al., 2002). However, although catalytic activity of XA21 is essential for full resistance levels, the catalytically impaired XA21 mutant maintains partial resistance activity (Andaya and 


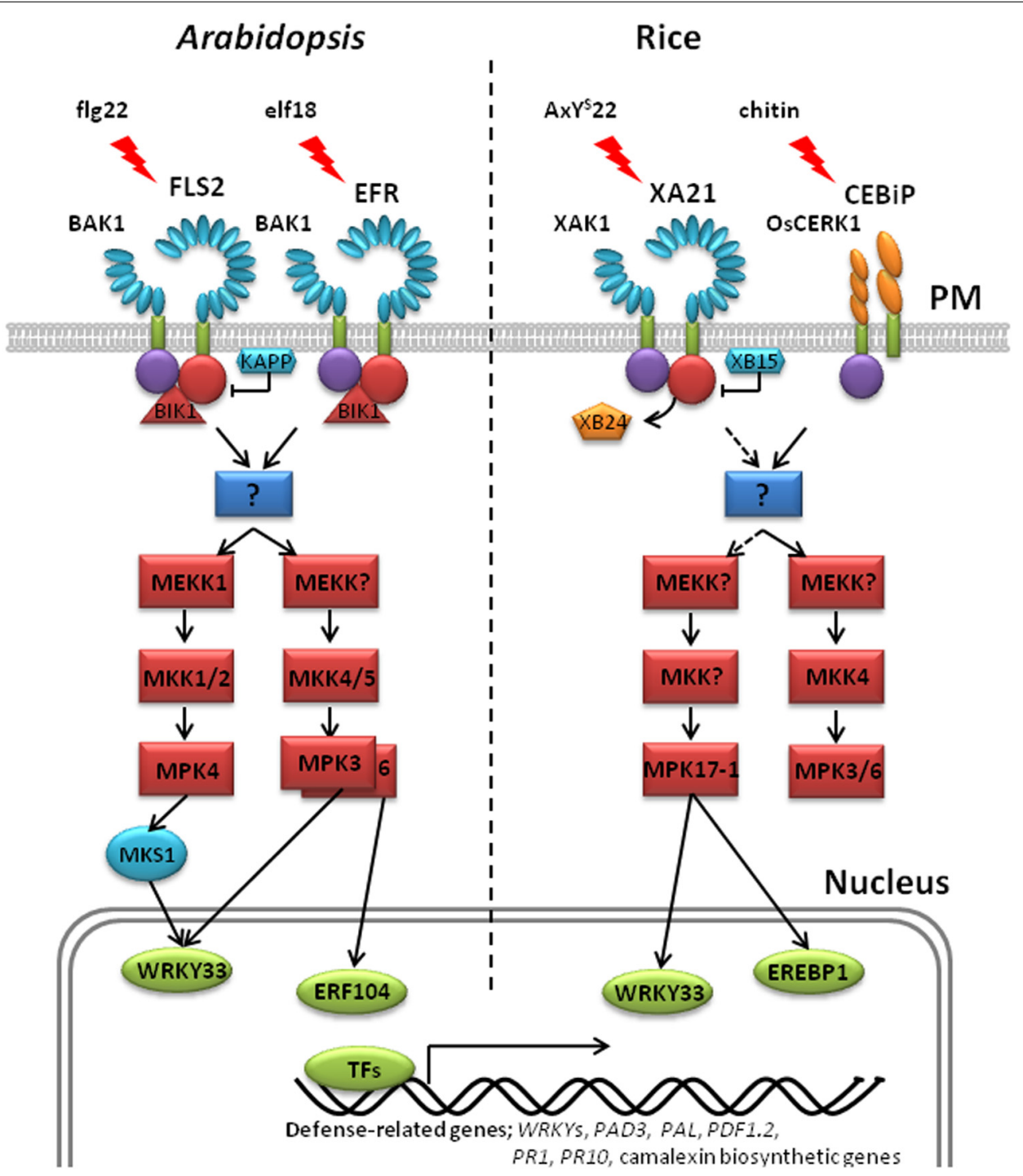

FIGURE 2 | Models for pattern recognition receptor-mediated phosphorylation pathways in Arabidopsis and rice. Left: Arabidopsis FLS2 and BAK1 associate with the membrane-associated cytoplasmic kinase Botrytis-induced kinase 1 (BIK1) in vitro and in vivo (Lu et al., 2010). In the resting state, Arabidopsis FLS2 interacts with BIK1. Flg22 perception induces FLS2 and BAK1 association and phosphorylation. Activated BAK1

phosphorylates BIK1, which in turn transphosphorylates the FLS2/BAK1 complex. Phosphorylated BIK1 is released from the FLS2/BAK1 complex to activate downstream intracellular signaling. No direct phosphorylation targets of FLS2 have yet been identified. At least two MAPK cascades are initiated downstream of activated FLS2, leading to the phosphorylation of the adaptor protein MKS1 and the transcription factors, AtWRKY33 and ERF104.

Kinase-associated protein phosphatase (KAPP), a PP2C, blocks the activated FLS2 signaling and attenuates the downstream immune response.

EFR-mediated immunity is believed to trigger the same MAPK cascades as

FLS2. Right: In the resting state, rice XA21 forms an in vivo complex with the
ATPase, XB24, and the XA21-associated kinase, XAK1. Association of XAK1 and $X A 21$ requires the $X A 21 \mathrm{JM}$ and kinase domains. Binding of $A x Y^{S} 22$ to $X A 21$ induces dissociation of $X A 21$ from $X B 24$ and activates $X A 21$, triggering autophosphorylation. Activated XA21 likely activates a MAPK cascade that includes MPK17-1, leading to the phosphorylation of the transcription factors, OsWRKY33 and OsEREBP1. Recruitment of XB15 to the XA21 JM domain and subsequent dephosphorylation of phosphorylated residue(s) attenuates XA21 signaling. Cleavage of XA21 and translocalization of the intracellular kinase domain to the nucleus is required for the XA21-mediated immune response (Park and Ronald, 2012). Unlike other well-characterized PRRs, the rice receptors CEBiP and OsCERK1 contain extracellular LysM (lysine motif) domains in place of LRR domains (Kaku etal., 2006; Shimizu et al., 2010). Upon chitin perception, the CEBiP and OsCERK1 complex activates MAPK cascades. In Arabidopsis and rice, phosphorylation of transcription factors leads to large-scale transcriptional reprogramming, including the activation of WRKYs, PAD3, PAL, PRs, PDF1.2, and camalexin biosynthetic genes.
Ronald, 2003). The partial resistance is comparable to that of transgenic lines expressing XA21D, an XA21 family member consisting of an LRR domain but lacking a kinase domain, indicating that XA21 catalytic activity is not absolutely required for function. In Arabidopsis, a mutation in Lys ${ }^{898}$ of FLS2, which is analogous to
Lys $^{736}$ in XA21, abolishes MPK3 and MPK6 activation by flg22 when transiently overexpressed in protoplasts (Asai et al., 2002). Similarly, a kinase inactive mutation at Lys ${ }^{741}$ of EFR is unable to confer elf18-triggered ROS burst when transiently expressed in Nicotiana benthamiana (Schwessinger et al., 2011). 


\section{MITOGEN-ACTIVATED PROTEIN KINASES SERVE AS INTERNODES IN PRR-MEDIATED IMMUNITY}

Mitogen-associated protein kinase cascades are important for transmitting signals generated by receptors into cellular responses. Multiple studies support central roles for MAPK cascades in the immunity of Arabidopsis, parsley, tobacco, tomato, and rice (Frye et al., 2001; Zhang and Klessig, 2001; Cardinale et al., 2002; del Pozo et al., 2004; Pitzschke et al., 2009; Jung et al., 2010). Generally, MAP kinase kinase kinases (MAP3Ks, also called MEKKs) are activated by RKs. MAP3Ks activate downstream MAP kinase kinases (MAP2Ks, also called MKKs or MEKs) that in turn activate MAPKs (also called MPKs). MAPKs then target various proteins, which include other kinases, enzymes, and transcription factors (Khokhlatchev et al., 1998; Rodriguez et al., 2010). Genome-sequencing of Arabidopsis and rice have revealed the existence of approximately $60 \mathrm{MAP} 3 \mathrm{Ks}, 10 \mathrm{MAP} 2 \mathrm{Ks}$, and 20 MAPKs in Arabidopsis (Group, 2002) and at least 75 MAP3Ks, 8 MAP2Ks, and 17 MAPKs in rice (Reyna and Yang, 2006; Rao et al., 2010).

In Arabidopsis, many studies have shown that activated FLS2 triggers MAPK signaling cascades (Asai et al., 2002; Chinchilla et al., 2007; Pitzschke et al., 2009; Figure 2). Initially, MEKK1 activates MPK4 which was previously shown to negatively regulate the defense response (Andreasson et al., 2005). At the MAPK kinase level, flg22-induced activation of MPK3/4/6 is dependent on MKK1/2, while MPK3 and MPK6 are also activated by MKK4 (Meszaros et al., 2006; Gao et al., 2008; Qiu et al., 2008b). Thus, two simultaneous MAPK cascades are postulated. The first consists of an unknown MEKK-MKK4/5-MPK3/6 and acts positively on FLS2-mediated signaling. The other consists of MEKK1MKK1/2-MPK4 and acts negatively on the pathway (Nicaise et al., 2009). A physical interaction between MEKK1 and FLS2 has not been observed. Therefore, researchers are searching for signaling intermediates that function upstream of MEKK1 that would link FLS2 with the key MAPK cascades.

Elongation factor-Tu receptor-mediated signaling in Arabidopsis is thought to utilize a similar signal transduction pathway with FLS2. In-gel assays detect a rapid activation of MAPKs in EFRmediated immune response after elf18 treatment (Zipfel et al., 2006). Treatment with both flg 22 and elf18 at the same time induces the same MAPKs without an additive effect, indicating that these kinases belong to the same cellular pool of enzymes. These results suggest that PRR-mediated signaling induced by the two conserved microbial signatures, elf18 and flg22, converge at a step upstream of these kinases.

The role of MAPK cascades in PRR-mediated immunity has also been investigated in rice. For example, OsMPK3 [previously named OsBIMK1 (Song and Goodman, 2002)] and OsMPK171 [previously named OsBWMK1 (He et al., 1999)] both interact with XBs, suggesting that these MAP kinases are components of the XA21-mediated signaling pathway (Seo et al., 2011). OsMPK3 suppressing plants display enhanced resistance to Xoo, suggesting that it serves as negative regulator in the XA21-mediated response. In contrast, OsMPK17-1 knockouts displayed increased susceptibility to Xoo, suggesting a positive role in XA21-mediated immunity. OsMPK3/6 and OsMKK4 are activated by chitin (Kishi-Kaboshi et al., 2010; Kim et al., 2012).

\section{MAPKs PHOSPHORYLATE TRANSCRIPTION FACTORS}

Transcriptional reprogramming of immune responses in the nucleus is regulated by transcription factors including the WRKY and ethylene-responsive factor [ERF, also called ethyleneresponsive element binding protein (EREBP)] families (Gutterson and Reuber, 2004; Ishihama and Yoshioka, 2012). In animals, MAPKs are activated and then often translocate to the nucleus where MAPKs will directly or indirectly phosphorylate transcription factors (Harding et al., 2005; Rodriguez et al., 2010). Examples of nuclear localization of MAPKs have been reported in Arabidopsis and rice (Cheong et al., 2003; Yoo et al., 2008; Koo et al., 2009). Therefore, WRKY proteins and EREBPs constitute an important link between pathogen-activated MAPK signaling pathways and downstream transcriptional reprogramming.

High-density protein microarrays, employed to identify downstream factors of MAPKs in Arabidopsis, revealed that many WRKYs are directly regulated by MAPKs (Popescu et al., 2009). For example, Arabidopsis WRKY33 (AtWRKY33) is induced by conserved microbial signatures, such as the oomycete-derived peptide Pep25 (Lippok et al., 2007). Subsequent experiments showed that AtWRKY33 is phosphorylated by MPK3/MPK6 in vivo in response to Botrytis cinerea infection and by MPK4 at least in vitro (Mao et al., 2011). Phosphorylation of AtWRKY33 inhibits the growth of pathogenic fungi and bacteria by promoting the production of camalexin, a major antimicrobial phytoalexin. Mutation of MPK3/MPK6 phosphorylation sites in AtWRKY33 compromises its ability to complement the camalexin induction in the AtWRKY mutant. Another transcription factor, ethylene response factor (ERF104), is directly associated and phosphorylated by MPK6 but not MPK3 (Bethke et al., 2009). Perception of flg22 via FLS2 induces disruption of the MPK6/ERF104 complex, releasing ERF104 to its target promoters including PDF1.2 (plant defensin 1.2).

There is an increasing body of evidence that suggests MAPKs also regulate transcription factors indirectly. Two WRKY transcription factors AtWRKY25 and AtWRKY33 interact with MPK4 substrate 1 (MKS1) in yeast, suggesting that these WRKYs regulate gene expression downstream of MPK4 (Andreasson et al., 2005). It was later reported that AtWRKY33 also forms an in vivo complex with MPK4 and MKS1 (Qiu et al., 2008a). However, although MKS1 is directly associated with AtWRKY33 and is phosphorylated by MPK4, no interaction has been detected between AtWRKY33 and MPK4 (Andreasson et al., 2005; Qiu et al., 2008a). This suggests MPK4 and AtWRKY33 associate indirectly and require the adaptor protein MKS1 for their interaction (Qiu et al., 2008a). Following pathogen perception, the MKS1AtWRKY33 complex binds the phytoalexin deficient 3 (PAD3) promoter, which promotes camalexin synthesis.

To date, there are only a few reports suggesting that MAPKs phosphorylate rice transcription factors in response to pathogen infection. For example, OsMPK17-1 phosphorylates OsWRKY33 in vitro, which binds to the $\mathrm{W}$-box element in the OsPR1 gene promoter (Koo et al., 2009). OsMPK17-1 also phosphorylates the transcription factor OsEREBP1 in vitro (Cheong etal., 2003). Transient co-expression of OsMPK17-1 and OsEREBP1 in Arabidopsis protoplasts elevates the expression of the $\beta$-glucuronidase reporter gene driven by the ethylene-responsive element GCC box 
in several basic PR gene promoters. Thus, OsMPK17-1 is involved in rice defense signal transduction and is responsible for the direct phosphorylation of a transcription factor(s).

Although a role for MAPK-mediated phosphorylation of WRKYs has not been demonstrated for XA21-mediated immunity, several WRKYs interact directly with XA21 in yeast. For example, OsWRKY62, identified as XB10 in a yeast two-hybrid screen using the XA21 intracellular domain as bait, interacts with the XA21 kinase domain in rice protoplasts (Park and Ronald, 2012) and negatively regulates XA21-mediated immunity (Peng etal., 2008). Transgenic rice plants overexpressing OsWRKY62 are compromised in XA21-mediated immunity and are impaired in the activation the defense-related genes OsPR1 and OsPR10 (Peng et al., 2008). Additionally, OsWRKY76 was recently shown to negatively regulate XA21-mediated immunity when challenged with Xoo (Seo et al., 2011). Although these studies indicate a functional link between OsWRKYs and XA21-mediated immunity, XA21 has not been shown to directly phosphorylate the WRKYs, thus the role of phosphorylation is unknown.

\section{CONCLUSION AND PERSPECTIVES}

Recognition of conserved microbial signatures by PRRs is critical to plant survival. PRR activation induces rapid autophosphorylation, leading to phosphorylation of many other proteins. Despite the importance of phosphorylation in PRR-mediated immunity, only a few phosphorylation sites of PRRs have been identified. Those phosphorylation sites were initially found by targeted mutagenesis. Although recent advances in phosphoproteomic analyses using mass spectrometry have greatly expanded our capability to identify phosphopeptides (Benschop et al., 2007; Nuhse et al., 2007; Stulemeijer and Joosten, 2008; Kersten et al., 2009), this approach has not yet lead to the identification of additional in vivo PRR phosphosites. This lack of success may be due to the observed rapid endocytosis and/or degradation of PRRs following perception of conserved microbial signatures (Robatzek et al., 2006; Robatzek, 2007; Chen et al., 2010a), which likely serves as a

\section{REFERENCES}

Aifa, S., Frikha, F., Miled, N., Johansen, K., Lundstrom, I., and Svensson, S. P. (2006). Phosphorylation of Thr654 but not Thr669 within the juxtamembrane domain of the EGF receptor inhibits calmodulin binding. Biochem. Biophys. Res. Commun. 347, 381-387.

Andaya, C. B., and Ronald, P. C. (2003). A catalytically impaired mutant of the rice Xa21 receptor kinase confers partial resistance to Xanthomonas oryzae pv. oryzae. Physiol. Mol. Plant Pathol. 62, 203-208.

Andreasson, E., Jenkins, T., Brodersen, P., Thorgrimsen, S., Petersen, N. H., Zhu, S., Qiu, J. L., Micheelsen, P., Rocher, A., Petersen, M., Newman, M. A., Bjorn Nielsen, H., Hirt, H., Somssich, I., Mattsson, O., and Mundy, J. (2005). The MAP kinase substrate MKS1 is a regulator of plant defense responses. EMBO J. 24, 2579-2589.

Asai, T., Tena, G., Plotnikova, J., Willmann, M. R., Chiu, W. L., GomezGomez, L., Boller, T., Ausubel, F. M., and Sheen, J. (2002). MAP kinase signalling cascade in Arabidopsis innate immunity. Nature 415, 977-983.

Benschop, J. J., Mohammed, S., O’Flaherty, M., Heck, A. J., Slijper, M., and Menke, F. L. (2007). Quantitative phosphoproteomics of early elicitor signaling in Arabidopsis. Mol. Cell. Proteomics 6, 1198-1214.

Besant, P. G., and Attwood, P. V. (2005). Mammalian histidine kinases. Biochim. Biophys. Acta 1754, 281-290.

Bethke, G., Unthan, T., Uhrig, J. F., Poschl, Y., Gust, A. A., Scheel, D., and Lee, J. (2009). Flg22 regulates the release of an ethylene response factor substrate from MAP kinase 6

barrier to identifying PRR phosphorylation sites using mass spectrometry. Progress in mass spectrometric technology to enhance sensitivity of detection of low abundance phosphopeptides is needed to overcome this limitation. Once identified, such sites can be confirmed using independent techniques such as immunoblotting with anti-phospho-specific antibodies and in vivo genetic studies.

In addition to slow progress in identifying residues phosphorylated on the PRR itself, other proteins that could serve as targets of PRR phosphorylation have not yet been identified. Therefore, there is still a gap in our understanding of how precisely PRRs are able to initiate early signaling events such as activation of MAPKs, a rapid calcium influx and an oxidative burst. To answer these fundamental questions, it will be essential to identify such target proteins and to determine how these proteins regulate downstream events. Phosphoproteomic comparison is one method that can identify proteins that become phosphorylated during PRR-mediated immunity. For example, quantitative phosphoproteomic analyses performed on flg22- or xylanasetreated Arabidopsis cells successfully revealed several differentially phosphorylated proteins such as auxin efflux carriers and respiratory burst oxidase protein D (Nuhse et al., 2007; Stulemeijer and Joosten, 2008).

Another important goal is to identify the substrates of MAPKs that are phosphorylated during PRR-mediated immunity. To date, only a few transcription factors have been shown to be phosphorylated by MAPKs during PRR-mediated immune responses. Studies utilizing protein microarrays, protein complex immunoprecipitations, and phosphoproteomic analyses will continue to uncover additional transcription factors and other potential MAPK targets, further contributing to our understanding of the role of phosphorylation in plant immune responses.

\section{ACKNOWLEDGMENTS}

This work was supported by the National Institute of Health (NIH, GM55962) and the National Science Foundation (NSF, IOS-0817738).

in Arabidopsis thaliana via ethylene signaling. Proc. Natl. Acad. Sci. U.S.A 106, 8067-8072.

Boller, T., and Felix, G. (2009). A renaissance of elicitors: perception of microbe-associated molecular patterns and danger signals by patternrecognition receptors. Annu. Rev. Plant Biol. 60, 379-406.

Cardinale, F., Meskiene, I., Ouaked, F., and Hirt, H. (2002). Convergence and divergence of stressinduced mitogen-activated protein kinase signaling pathways at the level of two distinct mitogen-activated protein kinase kinases. Plant Cell 14, 703-711.

Carrera, A. C., Alexandrov, K., and Roberts, T. M. (1993). The conserved lysine of the catalytic domain of protein kinases is actively involved in the phosphotransfer reaction and not required for anchoring ATP.
Proc. Natl. Acad. Sci. U.S.A. 90, 442-446.

Chen, F., Gao, M. J., Miao, Y. S., Yuan, Y. X., Wang, M. Y., Li, Q., Mao, B. Z., Jiang, L. W., and He, Z. H. (2010a). Plasma membrane localization and potential endocytosis of constitutively expressed XA21 proteins in transgenic rice. Mol. Plant 3, 917-926.

Chen, X., Chern, M., Canlas, P. E., Jiang, C., Ruan, D., Cao, P., and Ronald, P. C. (2010b). A conserved threonine residue in the juxtamembrane domain of the XA21 pattern recognition receptor is critical for kinase autophosphorylation and XA21-mediated immunity. J. Biol. Chem. 285, 10454-10463.

Chen, X., Chern, M., Canlas, P. E., Ruan, D., Jiang, C., and Ronald, P. C. $(2010 \mathrm{c})$. An ATPase promotes autophosphorylation of the 
pattern recognition receptor XA21 and inhibits XA21-mediated immunity. Proc. Natl. Acad. Sci. U.S.A. 107, 8029-8034.

Cheong, Y. H., Moon, B. C., Kim, J. K., Kim, C. Y., Kim, M. C., Kim, I. H., Park, C. Y., Kim, J. C., Park, B. O., Koo, S. C., Yoon, H. W., Chung, W. S., Lim, C. O., Lee, S. Y., and Cho, M. J. (2003). BWMK1, a rice mitogenactivated protein kinase, locates in the nucleus and mediates pathogenesisrelated gene expression by activation of a transcription factor. Plant Physiol. 132, 1961-1972.

Chinchilla, D., Bauer, Z., Regenass, M., Boller, T., and Felix, G. (2006). The Arabidopsis receptor kinase FLS2 binds flg22 and determines the specificity of flagellin perception. Plant Cell 18, 465-476.

Chinchilla, D., Shan, L., He, P., De Vries, S., and Kemmerling, B. (2009). One for all: the receptor-associated kinase BAK1. Trends Plant Sci. 14, 535-541.

Chinchilla, D., Zipfel, C., Robatzek, S., Kemmerling, B., Nurnberger, T., Jones, J. D., Felix, G., and Boller, T. (2007). A flagellin-induced complex of the receptor FLS2 and BAK1 initiates plant defence. Nature 448 , 497-500.

Ciesla, J., Fraczyk, T., and Rode, W. (2011). Phosphorylation of basic amino acid residues in proteins: important but easily missed. Acta Biochim. Pol. 58, 137-148.

Dardick, C., and Ronald, P. (2006). Plant and animal pathogen recognition receptors signal through nonRD kinases. PLoS Pathog. 2, e2. doi: 10.1371/journal.ppat.0020002.

de la Fuente van Bentem, S., and Hirt, $H$. (2009). Protein tyrosine phosphorylation in plants: more abundant than expected? Trends Plant Sci. 14, 71-76.

del Pozo, O., Pedley, K. F., and Martin, G. B. (2004). MAPKKKalpha is a positive regulator of cell death associated with both plant immunity and disease. EMBO J. 23, 3072-3082.

Frei Dit Frey, N., Mbengue, M., Kwaaitaal, M., Nitsch, L., Altenbach, D., Haweker, H., Lozano-Duran, R., Njo, M. F., Beeckman, T., Huettel, B., Borst, J. W., Panstruga, R., and Robatzek, S. (2012). Plasma membrane calcium ATPases are important components of receptor-mediated signaling in plant immune responses and development. Plant Physiol. 159, 798-809.

Frye, C. A., Tang, D., and Innes, R. W. (2001). Negative regulation of defense responses in plants by a conserved MAPKK kinase. Proc. Natl. Acad. Sci. U.S.A. 98, 373-378.
Gao, M., Liu, J., Bi, D., Zhang, Z., Cheng, F., Chen, S., and Zhang, Y. (2008). MEKK1, MKK1/MKK2 and MPK4 function together in a mitogen-activated protein kinase cascade to regulate innate immunity in plants. Cell Res. 18, 1190-1198.

Ghelis, T. (2011). Signal processing by protein tyrosine phosphorylation in plants. Plant Signal. Behav. 6, 942-951.

Gomez-Gomez, L., Bauer, Z., and Boller, T. (2001). Both the extracellular leucine-rich repeat domain and the kinase activity of FSL2 are required for flagellin binding and signaling in Arabidopsis. Plant Cell 13, 1155-1163.

Gomez-Gomez, L., and Boller, T. (2000). FLS2: an LRR receptor-like kinase involved in the perception of the bacterial elicitor flagellin in Arabidopsis. Mol. Cell 5, 1003-1011.

Group, M. (2002). Mitogen-activated protein kinase cascades in plants: a new nomenclature. Trends Plant Sci. 7, 301-308.

Gutterson, N., and Reuber, T. L. (2004) Regulation of disease resistance pathways by AP2/ERF transcription factors. Curr. Opin. Plant Biol. 7, 465-471.

Harding, A., Tian, T., Westbury, E., Frische, E., and Hancock, J. F. (2005). Subcellular localization determines MAP kinase signal output. Curr. Biol. 15, 869-873.

He, C., Fong, S. H., Yang, D., and Wang, G. L. (1999). BWMK1, a novel MAP kinase induced by fungal infection and mechanical wounding in rice. Mol. Plant Microbe Interact. 12, 1064-1073.

Heese, A., Hann, D. R., GimenezIbanez, S., Jones, A. M., He, K., Li, J. Schroeder, J. I., Peck, S. C., and Rathjen, J. P. (2007). The receptor-like kinase SERK3/BAK1 is a central regulator of innate immunity in plants. Proc. Natl. Acad. Sci. U.S.A. 104 12217-12222.

Ishihama, N., and Yoshioka, H. (2012). Post-translational regulation of WRKY transcription factors in plant immunity. Curr. Opin. Plant Biol. (in press). doi: 10.1016/j.pbi. 2012.02.003

Jensen, O. N. (2004). Modificationspecific proteomics: characterization of post-translational modifications by mass spectrometry. Curr. Opin. Chem. Biol. 8, 33-41.

Jung, K. H., Cao, P., Seo, Y. S., Dardick, C., and Ronald, P. C. (2010). The rice kinase phylogenomics database: a guide for systematic analysis of the rice kinase super-family. Trends Plant Sci. 15, 595-599.
Kadota, Y., Goh, T., Tomatsu, H. Tamauchi, R., Higashi, K., Muto, S., and Kuchitsu, K. (2004). Cryptogeininduced initial events in tobacco BY-2 cells: pharmacological characterization of molecular relationship among cytosolic $\mathrm{Ca}(2+)$ transients, anion efflux and production of reactive oxygen species. Plant Cell Physiol. 45, 160-170.

Kaku, H., Nishizawa, Y., IshiiMinami, N., Akimoto-Tomiyama, C. Dohmae, N., Takio, K., Minami, E., and Shibuya, N. (2006). Plant cells recognize chitin fragments for defense signaling through a plasma membrane receptor. Proc. Natl. Acad. Sci. U.S.A. 103, 11086-11091.

Kersten, B., Agrawal, G. K., Durek, P., Neigenfind, J., Schulze, W., Walther D., and Rakwal, R. (2009). Plant phosphoproteomics: an update. Proteomics 9, 964-988.

Khokhlatchev, A. V., Canagarajah, B., Wilsbacher, J., Robinson, M., Atkinson, M., Goldsmith, E., and Cobb, M. H. (1998). Phosphorylation of the MAP kinase ERK2 promotes its homodimerization and nuclear translocation. Cell 93, 605-615.

Kim, S. H., Oikawa, T., Kyozuka, J. Wong, H. L., Umemura, K., KishiKaboshi, M., Takahashi, A., Kawano, Y., Kawasaki, T., and Shimamoto, K. (2012). The bHLH Rac immunityl (RAI1) is activated by OsRacl via OsMAPK3 and OsMAPK6 in rice immunity. Plant Cell Physiol. 53, 740-754.

Kishi-Kaboshi, M., Okada, K., Kurimoto, L., Murakami, S., Umezawa T., Shibuya, N., Yamane, H., Miyao, A., Takatsuji, H., Takahashi, A., and Hirochika, H. (2010). A rice fungal MAMP-responsive MAPK cascade regulates metabolic flow to antimicrobial metabolite synthesis. Plant J. 63, 599-612.

Koo, S. C., Moon, B. C., Kim, J. K., Kim, C. Y., Sung, S. J., Kim, M. C., Cho, M. J., and Cheong, Y. H. (2009). OsBWMK1 mediates SA-dependent defense responses by activating the transcription factor OsWRKY33. Biochem. Biophys. Res. Commun. 387, 365-370.

Korasick, D. A., Mcmichael, C., Walker, K. A., Anderson, J. C., Bednarek, S. Y. and Heese, A. (2010). Novel functions of stomatal cytokinesis-defective 1 (SCD1) in innate immune response against bacteria. J. Biol. Chem. 285, 23342-23350.

Lecourieux, D., Mazars, C., Pauly, N., Ranjeva, R., and Pugin, A. (2002). Analysis and effects of cytosolic free calcium increases in response to elicitors in Nicotiana plumbaginifolia cells. Plant Cell 14, 2627-2641.

Lee, I., Seo, Y. S., Coltrane, D., Hwang, S., Oh, T., Marcotte, E. M., and Ronald, P. C. (2011). Genetic dissection of the biotic stress response using a genome-scale gene network for rice. Proc. Natl. Acad. Sci. U.S.A. 108, 18548-18553.

Lee, S. W., Han, S. W., Sririyanum, M., Park, C. J., Seo, Y. S., and Ronald, P. C. (2009). A type Isecreted, sulfated peptide triggers XA21-mediated innate immunity. Science 326, 850-853.

Li, J., Wen, J., Lease, K. A., Doke, J. T., Tax, F. E., and Walker, J. C. (2002). BAK1, an Arabidopsis LRR receptor-like protein kinase, interacts with BRI1 and modulates brassinosteroid signaling. Cell 110, 213-222.

Lippok, B., Birkenbihl, R. P., Rivory, G., Brummer, J., Schmelzer, E., Logemann, E., and Somssich, I. E. (2007). Expression of AtWRKY33 encoding a pathogen- or PAMPresponsive WRKY transcription factor is regulated by a composite DNA motif containing W box elements. Mol. Plant Microbe Interact. 20, 420-429.

Liu, G. Z., Pi, L. Y., Walker, J. C., Ronald, P. C., and Song, W. Y. (2002). Biochemical characterization of the kinase domain of the rice disease resistance receptor-like kinase XA21. J. Biol. Chem. 277, 20264-20269.

Lu, D., Lin, W., Gao, X., Wu, S., Cheng, C., Avila, J., Heese, A., Devarenne, T. P., He, P., and Shan, L. (2011). Direct ubiquitination of pattern recognition receptor FLS2 attenuates plant innate immunity. Science 332, 1439-1442.

Lu, D., Wu, S., Gao, X., Zhang, Y., Shan, L., and He, P. (2010). A receptorlike cytoplasmic kinase, BIK1, associates with a flagellin receptor complex to initiate plant innate immunity. Proc. Natl. Acad. Sci. U.S.A. 107, 496-501.

Mao, G., Meng, X., Liu, Y., Zheng, Z., Chen, Z., and Zhang, S. (2011). Phosphorylation of a WRKY transcription factor by two pathogen-responsive MAPKs drives phytoalexin biosynthesis in Arabidopsis. Plant Cell 23, 1639-1653.

Meszaros, T., Helfer, A., Hatzimasoura, E., Magyar, Z., Serazetdinova, L., Rios, G., Bardoczy, V., Teige, M., Koncz, C., Peck, S., and Bogre, L. (2006). The Arabidopsis MAP kinase kinase MKK1 participates in defence responses to the bacterial elicitor flagellin. Plant J. 48, 485-498. 
Monaghan, J., and Zipfel, C. (2012). Plant pattern recognition receptor complexes at the plasma membrane. Curr. Opin. Plant Biol. 15, 1-9.

Nakagami, H., Sugiyama, N., Mochida, K., Daudi, A., Yoshida, Y., Toyoda, T., Tomita, M., Ishihama, Y., and Shirasu, K. (2010). Large-scale comparative phosphoproteomics identifies conserved phosphorylation sites in plants. Plant Physiol. 153, 11611174.

Nam, K. H., and Li, J. (2002). BRI1/BAK1, a receptor kinase pair mediating brassinosteroid signaling. Cell 110, 203-212.

Navazio, L., Moscatiello, R., Bellincampi, D., Baldan, B., Meggio, F., Brini, M., Bowler, C., and Mariani, P. (2002). The role of calcium in oligogalacturonide-activated signalling in soybean cells. Planta 215 , 596-605.

Nicaise, V., Roux, M., and Zipfel, C. (2009). Recent advances in PAMPtriggered immunity against bacteria: pattern recognition receptors watch over and raise the alarm. Plant Physiol. 150, 1638-1647.

Nuhse, T. S., Bottrill, A. R., Jones, A. M., and Peck, S. C. (2007). Quantitative phosphoproteomic analysis of plasma membrane proteins reveals regulatory mechanisms of plant innate immune responses. Plant J. 51 , 931-940.

Nurnberger, T., Brunner, F., Kemmerling, B., and Piater, L. (2004). Innate immunity in plants and animals: striking similarities and obvious differences. Immunol. Rev. 198, 249-266.

Olsen, J. V., Blagoev, B., Gnad, F., Macek, B., Kumar, C., Mortensen, P., and Mann, M. (2006). Global, in vivo, and site-specific phosphorylation dynamics in signaling networks. Cell 127, 635-648.

Park, C. J., Peng, Y., Chen, X., Dardick, C., Ruan, D., Bart, R., Canlas, P. E., and Ronald, P. C. (2008). Rice $\mathrm{XB15}$, a protein phosphatase $2 \mathrm{C}$, negatively regulates cell death and XA21mediated innate immunity. PLoS Biol. 6, e231. doi: 10.1371/journal.pbio.0060231.

Park, C. J., and Ronald, P. C. (2012). Cleavage and nuclear localization of the rice XA21 immune receptor. Nat. Commun. 3, 920.

Peng, Y., Bartley, L. E., Chen, X., Dardick, C., Chern, M., Ruan, R., Canlas, P. E., and Ronald, P. C. (2008). OsWRKY62 is a negative regulator of basal and Xa21-mediated defense against Xanthomonas oryzae pv. oryzae in rice. Mol. Plant 1, 446-458.
Pitzschke, A., Schikora, A., and Hirt, H. (2009). MAPK cascade signalling networks in plant defence. Curr. Opin. Plant Biol. 12, 421-426.

Popescu, S. C., Popescu, G. V., Bachan, S., Zhang, Z., Gerstein, M., Snyder M., and Dinesh-Kumar, S. P. (2009). MAPK target networks in Arabidopsis thaliana revealed using functional protein microarrays. Genes Dev 23,80 .

Qiu, J. L., Fiil, B. K., Petersen, K. Nielsen, H. B., Botanga, C. J., Thorgrimsen, S., Palma, K., SuarezRodriguez, M. C., Sandbech-Clausen, S., Lichota, J., Brodersen, P., Grasser, K. D., Mattsson, O., Glazebrook, J., Mundy, J., and Petersen, M. (2008a). Arabidopsis MAP kinase 4 regulates gene expression through transcription factor release in the nucleus. EMBO J. 27, 2214-2221.

Qiu, J. L., Zhou, L., Yun, B. W. Nielsen, H. B., Fiil, B. K., Petersen, K., Mackinlay, J., Loake, G. J., Mundy, J., and Morris, P. C. (2008b). Arabidopsis mitogen-activated protein kinase kinases MKK1 and MKK2 have overlapping functions in defense signaling mediated by MEKK1, MPK4 and MKS1. Plant Physiol. 148, 212-222.

Rao, K. P., Richa, T., Kumar, K., Raghuram, B., and Sinha, A. K. (2010). In silico analysis reveals 75 members of mitogen-activated protein kinase kinase kinase gene family in rice. DNA Res. 17, 139-153.

Reyna, N. S., and Yang, Y. (2006). Molecular analysis of the rice MAP kinase gene family in relation to Magnaporthe grisea infection. Mol. Plant Microbe Interact. 19, 530-540.

Robatzek, S. (2007). Vesicle trafficking in plant immune responses. Cell. Microbiol. 9, 1-8.

Robatzek, S., Chinchilla, D., and Boller, T. (2006). Ligand-induced endocytosis of the pattern recognition receptor FLS2 in Arabidopsis. Genes Dev. 20 537-542.

Rodriguez, M. C., Petersen, M., and Mundy, J. (2010). Mitogenactivated protein kinase signaling in plants. Annu. Rev. Plant Biol. 61, 621-649.

Ronald, P. C., and Beutler, B. (2010). Plant and animal sensors of conserved microbial signatures. Science 330, 1061-1064.

Roux, M., Schwessinger, B., Albrecht, C., Chinchilla, D., Jones, A., Holton, N., Malinovsky, F. G., Tor, M., De Vries, S., and Zipfel, C. (2011). The Arabidopsis leucine-rich repeat receptor-like kinases BAK1/SERK3 and BKK1/SERK 4 are required for innate immunity to hemibiotrophic and biotrophic pathogens. Plant Cell 23, 2440-2455.

Schulze, B., Mentzel, T., Jehle, A. K. Mueller, K., Beeler, S., Boller, T., Felix, G., and Chinchilla, D. (2010). Rapid heteromerization and phosphorylation of ligand-activated plant transmembrane receptors and their associated kinase BAK1. J. Biol. Chem. 285, 9444-9451.

Schwessinger, B., and Ronald, P. C. (2012). Plant innate immunity: perception of conserved microbial signatures. Annu. Rev. Plant Biol. 63 451-482.

Schwessinger, B., Roux, M., Kadota, Y., Ntoukakis, V., Sklenar, J., Jones, A., and Zipfel, C. (2011). Phosphorylation-dependent differential regulation of plant growth, cell death, and innate immunity by the regulatory receptor-like kinase BAK1. PLoS Genet. 7, e1002046. doi: 10.1371/journal.pgen.1002046.

Segonzac, C., and Zipfel, C. (2011). Activation of plant patternrecognition receptors by bacteria. Curr. Opin. Microbiol. 14, 54-61.

Seo, Y. S., Chern, M., Bartley, L. E., Han, M., Jung, K. H., Lee, I., Walia, H., Richter, T., Xu, X., Cao, P., Bai, W., Ramanan, R., Amonpant, F., Arul, L., Canlas, P. E., Ruan, R., Park, C. J., Chen, X., Hwang, S., Jeon, J. S., and Ronald, P. C. (2011). Towards establishment of a rice stress response interac tome. PLoS Genet. 7, e1002020. doi: 10.1371/journal.pgen.1002020.

Shan, L., He, P., Li, J., Heese, A., Peck, S. C., Nurnberger, T., Martin, G B., and Sheen, J. (2008). Bacterial effectors target the common signaling partner BAK1 to disrupt multiple MAMP receptor-signaling complexes and impede plant immunity. Cell Host Microbe 4, 17-27.

Shimizu, T., Nakano, T., Takamizawa, D., Desaki, Y., Ishii-Minami, N. Nishizawa, Y., Minami, E., Okada, K., Yamane, H., Kaku, H., and Shibuya, N. (2010). Two LysM receptor molecules, CEBiP and OsCERK1, cooperatively regulate chitin elicitor signaling in rice. Plant J. 64, 204-214.

Song, F., and Goodman, R. M. (2002). OsBIMK1, a rice MAP kinase gene involved in disease resistance responses. Planta 215, 997-1005.

Stulemeijer, I. J., and Joosten, M. H. (2008). Post-translational modification of host proteins in pathogentriggered defence signalling in plants. Mol. Plant Pathol. 9, 545-560.

Sugiyama, N., Nakagami, H., Mochida, K., Daudi, A., Tomita, M., Shirasu, K. and Ishihama, Y. (2008). Large-scale phosphorylation mapping reveals the extent of tyrosine phosphorylation in Arabidopsis. Mol. Syst. Biol. 4, 193.

Thiel, K. W., and Carpenter, G. (2007). Epidermal growth factor receptor juxtamembrane region regulates allosteric tyrosine kinase activation. Proc. Natl. Acad. Sci. U.S.A. 104, 19238-19243.

Wang, Y. S., Pi, L. Y., Chen, X., Chakrabarty, P. K., Jiang, J., De Leon, A. L., Liu, G. Z., Li, L., Benny, U., Oard, J., Ronald, P. C., and Song, W. Y. (2006). Rice XA21 binding protein 3 is a ubiquitin ligase required for full Xa21-mediated disease resistance. Plant Cell 18, 3635-3646.

Weintz, G., Olsen, J. V., Fruhauf, K., Niedzielska, M., Amit, I., Jantsch, J., Mages, J., Frech, C., Dolken, L., Mann, M., and Lang, R. (2010). The phosphoproteome of toll-like receptor-activated macrophages. Mol. Syst. Biol. 6, 371 .

Xu, W. H., Wang, Y. S., Liu, G. Z., Chen, X., Tinjuangjun, P., Pi, L. Y., and Song, W. Y. (2006). The autophosphorylated Ser686, Thr688, and Ser689 residues in the intracellular juxtamembrane domain of XA21 are implicated in stability control of rice receptor-like kinase. Plant J. 45, 740-751.

Yoo, S. D., Cho, Y. H., Tena, G., Xiong, Y., and Sheen, J. (2008). Dual control of nuclear EIN3 by bifurcate MAPK cascades in $\mathrm{C} 2 \mathrm{H} 4$ signalling. Nature 451, 789-795.

Zhang, J., Li, W., Xiang, T., Liu, Z., Laluk, K., Ding, X., Zou, Y., Gao, M., Zhang, X., Chen, S., Mengiste, T., Zhang, Y., and Zhou, J. M. (2010). Receptor-like cytoplasmic kinases integrate signaling from multiple plant immune receptors and are targeted by a Pseudomonas syringae effector. Cell Host Microbe 7, 290-301.

Zhang, S., and Klessig, D. F. (2001). MAPK cascades in plant defense signaling. Trends Plant Sci. 6, 520-527.

Zipfel, C., Kunze, G., Chinchilla, D., Caniard, A., Jones, J. D., Boller, T., and Felix, G. (2006). Perception of the bacterial PAMP EF-Tu by the receptor EFR restricts Agrobacteriummediated transformation. Cell 125, 749-760.

Conflict of Interest Statement: The authors declare that the research was conducted in the absence of any commercial or financial relationships that 
could be construed as a potential conflict of interest.

Received: 08 May 2012; paper pending published: 01 June 2012; accepted: 18 July 2012; published online: 03 August 2012.
Citation: Park C-J, Caddell DF and Ronald PC (2012) Protein phosphorylation in plant immunity: insights into the regulation of pattern recognition receptor-mediated signaling. Front. Plant Sci. 3:177. doi: 10.3389/fpls.2012.00177
This article was submitted to Frontiers in Plant Proteomics, a specialty of Frontiers in Plant Science.

Copyright (c) 2012 Park, Caddell and Ronald. This is an open-access article distributed under the terms of the Creative
Commons Attribution License, which permits use, distribution and reproduction in other forums, provided the original authors and source are credited and subject to any copyright notices concerning any third-party graphics etc. 